\title{
ГОСУДАРСТВЕННАЯ ПОДДЕРЖКА РАЗВИТИЯ ПРЕДПРИНИМАТЕЛЬСТВА В РЕСПУБЛИКЕ КАЗАХСТАН
}

\author{
Болатханова 3. А. к. э. н., дочент, \\ Сыздыков Е. К. к. э. н., дочент
}

Казахстан, Алматы, Алматинский технологический университет

DOI: https://doi.org/10.31435/rsglobal_ijite/01062018/5656

\section{ARTICLE INFO}

Received 12 April 2018

Accepted 09 May 2018

Published 01 June 2018

\section{KEYWORDS}

small business development, the program "business Road map 2020»

(C) 2018 The Authors.

\begin{abstract}
One of the priority directions of the economic reform, currently being carried out in Kazakhstan, is the formation and development of small business. The society is increasingly aware that small business is one of the key conditions for the formation of market mechanisms and is an integral part of the modern market system. Small business is not only a necessary link in the creation of a market system of management, but also the most essential element in the social transformation of society.

The state policy in the Republic of Kazakhstan regarding business is aimed at the formation of the middle class, through the development of small entrepreneurship, focused on the creation of new high-tech industries with the greatest added value.
\end{abstract}

Одним из приоритетных направлений экономической реформы, производимой в настоящее время в Казахстане, является становление и развитие малого и среднего бизнеса. Общество все больше осознает, что малый бизнес представляет собой одно из ключевых условий формирования рыночных механизмов и является составляющей частью современной рыночной системы. Малый бизнес является не только необходимым звеном в создании рыночной системы хозяйствования, но и наиболее существенным элементом в социальном преобразовании общества.

Казахстан провозгласил курс на формирование социально-ориентированного рыночного общества, который требует радикальных преобразований, направленных на преодоление монополизма и развития конкуренции. Одним из долгосрочных приоритетов социально-экономической политики Республики Казахстан является экономический рост, который включает в себя становление и развитие малого и среднего бизнеса, предпринимательства. Развитие предпринимательства в республике - один из приоритетов экономической политики государства. С самого начала вступления в рыночную экономику Президент РК дал всем понять, что малый и средний бизнес - стержень экономики, ее стратегический резерв.

Государственная политика в Республике Казахстан в отношении бизнеса нацелена на формирование среднего класса, путем развития малого предпринимательства, ориентированного на создание новых высокотехнологичных производств с наибольшей добавленной стоимостью.

Правительство Республики Казахстан, центральные и местные исполнительные органы через систему государственной поддержки содействуют в получении субъектами предпринимательства современного оборудования и технологий, разрабатывают и осуществляют мероприятия по созданию сети технопарков, лизинговых центров, центров малой инновационной деятельности, венчурных фирм и других объектов инфраструктуры, создаваемых в целях поддержки субъектов предпринимательства.

Выпуск продукции субъектами малого и среднего предпринимательства за 2017 год составил 21147,6 млрд. тенге. В общем количестве субъектов МСП доля индивидуальных предпринимателей составила 65,2%, юридических лиц малого предпринимательства - 18,2 \%, крестьянских или фермерских хозяйств - 16,4\%, юридических лиц среднего предпринимательства - 0,2\% (таблица 1). (1). Из сравнительного анализа (рис. 1) виден значительный рост выпуска продукции и численности субъектов малого и среднего 
предпринимательства. Несмотря на количественный рост предприятий, значительная часть зарегистрированных является не действующими. Однако малый и средний бизнес Казахстана мог бы развиваться быстрее. Развитие малого и среднего бизнеса в региональном аспекте характеризуется дифференциацией.

Таблица 1. Основные показатели деятельности субъектов МСП за 2017 г.

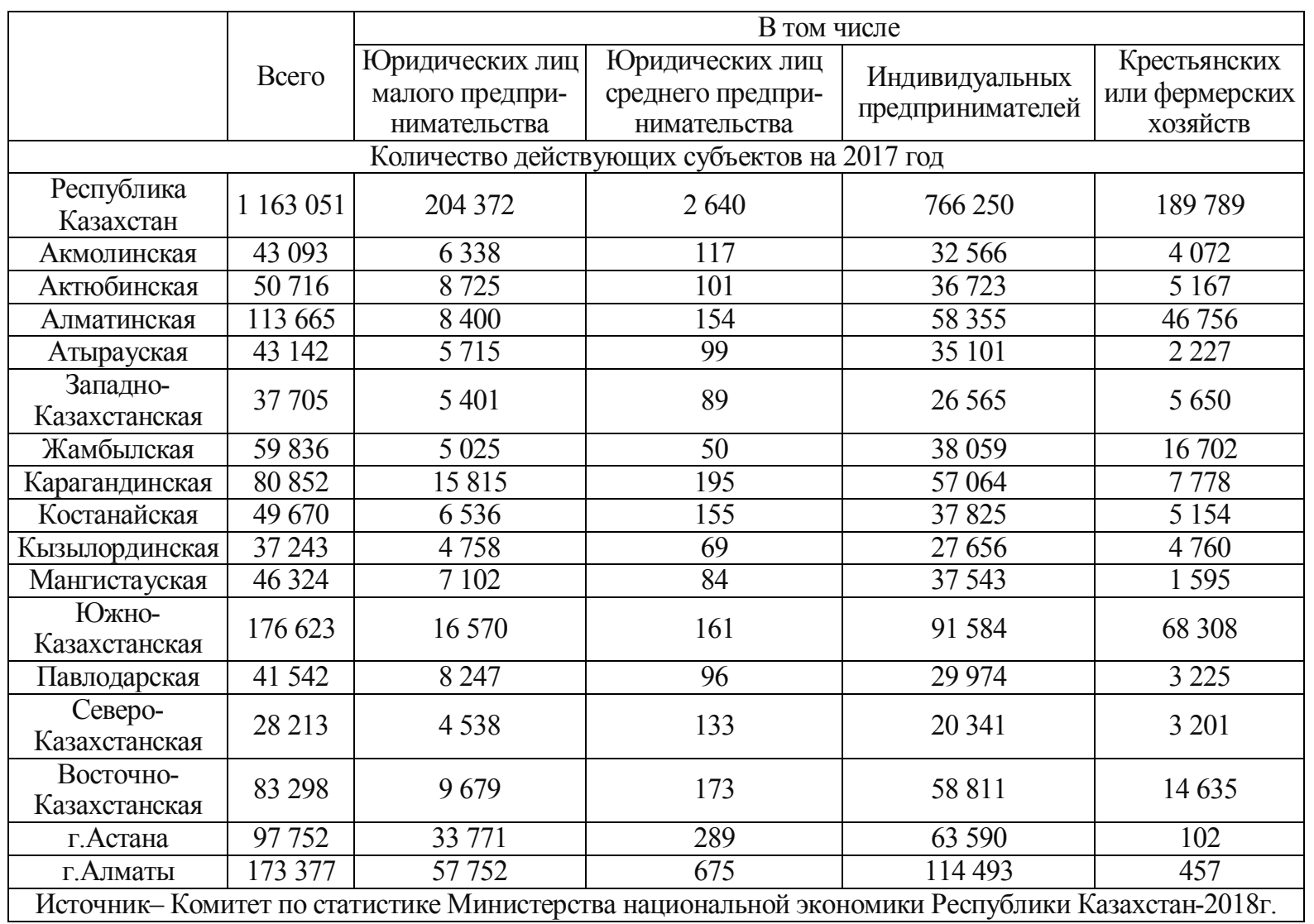

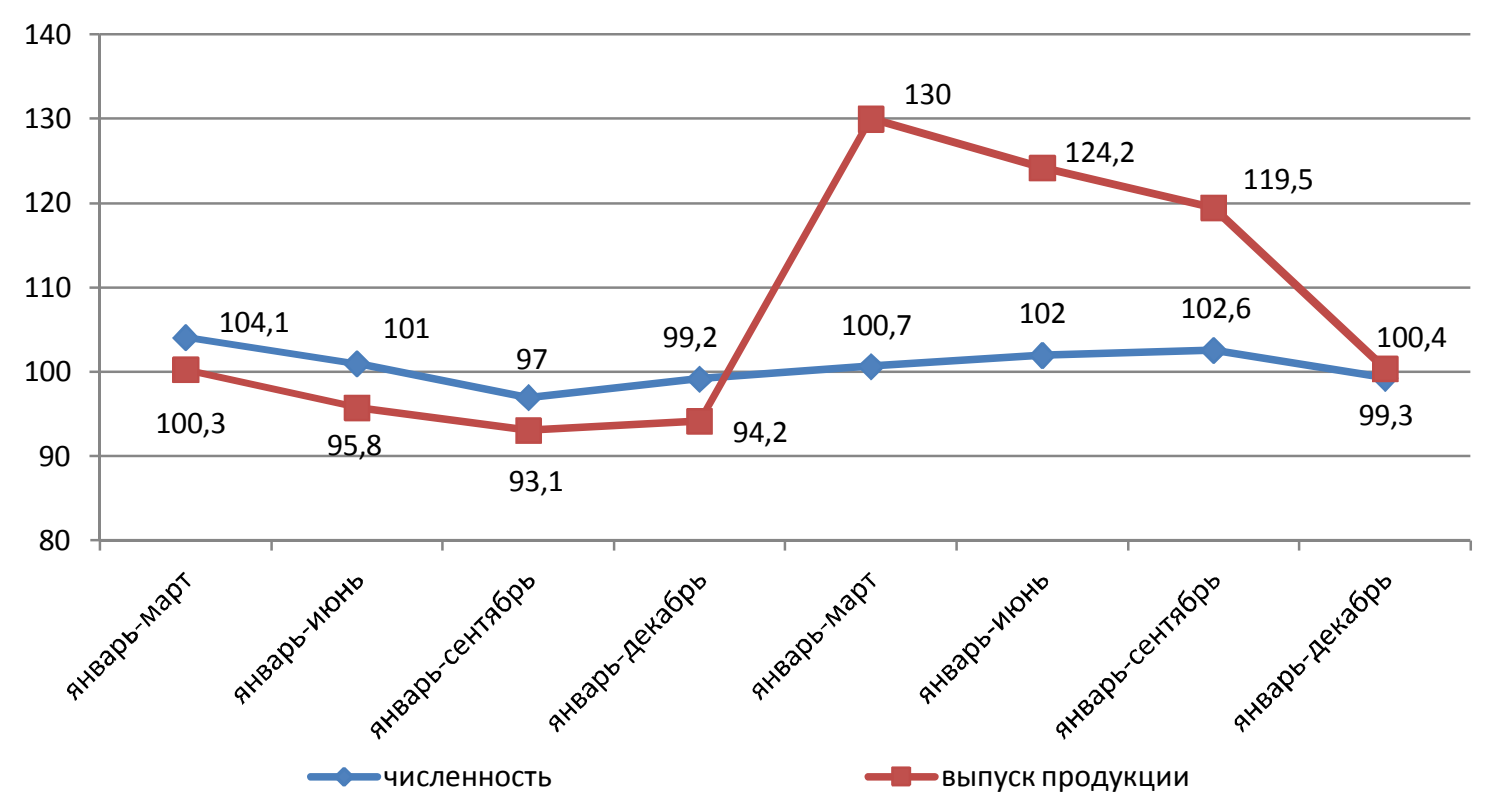

Рис. 1. Сравнительный анализ деятельности субъектов МСП за 2016-2017 годы

Источник- Комитет по статистике Министерства национальной экономики Республики Казахстан 
С 2016 года наблюдается активный рост кредитования МСБ. Число выданных банками кредитов увеличилось в 2,3 раза с 2015 года. По сравнению с 2015 годом объем кредитов увеличился на $29 \%$ и составил 3 трлн тенге.

Однако, по данным АБР, только 19 \% МСП получают кредиты, в то время как остальные рефинансируют доход или берут займы из других источников. Это связано с тем, что большинство предприятий имеют плохую кредитную историю или не имеют необходимых документов.

Направление кредитов отражает основные виды деятельности предприятий: торговля (37\%), строительство (13\%), промышленность (13\%) и другие отрасли, не связанные с основными секторами экономики (24\%).

Согласно статистике, доля МСБ в ВВП Казахстана составляет лишь $26 \%$, для сравнения, в европейских странах данный показатель в два раза больше и МСБ представляет 99 \% всего европейского бизнеса и обеспечивает работой половину работающего населения.

Государственное регулирование предпринимательской деятельности предполагает значительную степень управляемости политической и экономической системы, высокий уровень профессионализма государственных служащих, эффективность проводимой политики в отношении бизнеса, развитую систему негосударственных организаций, принципы открытой отчетности и подконтрольности органов власти, отсутствие коррупционного взаимодействия бизнеса и органов власти.

Перспективным направлением на ближайшие годы остаются программа «Дорожная карта бизнеса 2020», которая разработана для реализации послания Президента Республики Казахстан Н.А. Назарбаева народу Казахстана «Новое десятилетие - Новый экономический подъем - Новые возможности Казахстана» и Стратегического плана развития Казахстана до 2020 года и «Казахстан - 2050». Целью Программы «Дорожная карта бизнеса 2020» является обеспечение устойчивого и сбалансированного роста регионального предпринимательства в несырьевых секторах экономики, а также сохранение действующих и создание новых постоянных рабочих мест (2).

Реализация Программы осуществляется по трем направлениям: поддержка новых бизнес-инициатив; оздоровление предпринимательского сектора; поддержка экспортоориентированных производств.

В 2015 году стартовал 2-й этап - (2015 по 2020) по двум направлениям: поддержка новых проектов; поддержка экспортеров.

В ходе реализации Программы «Дорожная карта занятости 2020» планируется достижение к 2018 году следующих результатов: уровень бедности не будет превышать 6 \%; уровень безработицы не будет превышать $5 \%$; - доля продуктивно занятых в общем числе самостоятельно занятого населения увеличится до 64,5 \% (3).

По состоянию на 1 апреля 2018 года количество действующих субъектов МСП по сравнению с соответствующей датой предыдущего года увеличилось на $1,4 \%$. В общем количестве субъектов МСП доля индивидуальных предпринимателей составила $65,1 \%$, юридических лиц малого предпринимательства - 18,5\%, крестьянских или фермерских хозяйств - 16,2 \%, юридических лиц среднего предпринимательства - 0,2 \% (таблица 2).

Сравнительный анализ развития сектора малого и среднего предпринимательства в регионах РК (табл. 2.) позволяет сделать следующие выводы:

- по количеству активных субъектов малого и среднего предпринимательства традиционно лидируют г. Алматы, ЮКО и Алматинская область;

- г. Алматы является регионом с наибольшим количеством предприятий малого и среднего предпринимательства; имеет наибольшие показатели выпуска продукции малого и среднего предпринимательства и численности занятого в нем населения;

- в целом в РК за 2005-2017гг. наблюдается положительная тенденция роста малого и среднего предпринимательства — более чем на $50 \%$. Наибольший рост единиц малого предпринимательства наблюдается в г. Астане;

- в гендерном аспекте в РК действует свыше $40 \%$ субъектов малого и среднего предпринимательства, возглавляемых женщинами, и чаще всего женщины возглавляют ИП, доля которых в среднем по РК составляет $85 \%$.

- наибольше количество человек занято в малом и среднем предпринимательстве г. Алматы (583 тыс. чел.), ЮКО (330 тыс. чел.), г. Астаны (288 тыс. чел.) и Алматинской области (284 тыс. чел.);

- региональном разрезе наибольший выпуск продукции осуществляют субъекты малого и среднего предпринимательства гг. Алматы и Астаны (47 \% общего выпуска продукции МСП РК). 
Таблица 2. Основные показатели деятельности субъектов МСП на 1 апреля 2018 года

\begin{tabular}{|c|c|c|c|c|c|c|}
\hline & \multirow[b]{2}{*}{ Всего } & \multicolumn{4}{|c|}{ В том числе } & \multirow{2}{*}{$\begin{array}{c}\text { Всего, в } \\
\text { процентах к } \\
\text { соответствую } \\
\text { щему периоду } \\
\text { предыдущего } \\
\text { года }\end{array}$} \\
\hline & & $\begin{array}{c}\text { Юридических } \\
\text { лиц малого } \\
\text { предприни- } \\
\text { мательства }\end{array}$ & $\begin{array}{c}\text { Юридических } \\
\text { лиц среднего } \\
\text { предпринима } \\
\text { тельства }\end{array}$ & $\begin{array}{c}\text { Индивидуаль } \\
\text { ных предпри- } \\
\text { нимателей }\end{array}$ & $\begin{array}{c}\text { Крестьянских } \\
\text { или } \\
\text { фермерских } \\
\text { хозяйств }\end{array}$ & \\
\hline \multicolumn{7}{|c|}{ Количество действующих субъектов МСП на 1 апреля 2018 года } \\
\hline $\begin{array}{c}\text { Республика } \\
\text { Казахстан }\end{array}$ & 1169576 & 216555 & 2607 & 760837 & 189577 & 101,4 \\
\hline Акмолинская & 42456 & 6691 & 111 & 31467 & 4187 & 102,6 \\
\hline Актюбинская & 51770 & 9364 & 97 & 37192 & 5117 & 105,0 \\
\hline Алматинская & 112051 & 9087 & 156 & 58050 & 44758 & 101,3 \\
\hline Атырауская & 44234 & 6324 & 108 & 35499 & 2303 & 104,6 \\
\hline $\begin{array}{c}\text { Западно- } \\
\text { Казахстанская }\end{array}$ & 38052 & 5639 & 95 & 26703 & 5615 & 103,8 \\
\hline Жамбылская & 60244 & 5505 & 47 & 38123 & 16569 & 100,1 \\
\hline Карагандинская & 80472 & 16521 & 190 & 56031 & 7730 & 101,5 \\
\hline Костанайская & 48576 & 6824 & 158 & 36492 & 5102 & 101,7 \\
\hline Кызылординская & 38758 & 4929 & 64 & 28551 & 5214 & 110,0 \\
\hline Мангистауская & 48251 & 7662 & 85 & 38735 & 1769 & 105,8 \\
\hline $\begin{array}{c}\text { Южно- } \\
\text { Казахстанская }\end{array}$ & 180818 & 17370 & 166 & 94004 & 69278 & 103,4 \\
\hline Павлодарская & 42162 & 8794 & 107 & 30048 & 3213 & 102,6 \\
\hline $\begin{array}{c}\text { Северо- } \\
\text { Казахстанская }\end{array}$ & 27829 & 4810 & 128 & 19683 & 3208 & 101,1 \\
\hline $\begin{array}{c}\text { Восточно- } \\
\text { Казахстанская } \\
\end{array}$ & 81481 & 10304 & 165 & 56209 & 14803 & 99,1 \\
\hline г.Астана & 100853 & 36837 & 252 & 63636 & 128 & 104,8 \\
\hline г.Алматы & 171569 & 59894 & 678 & 110414 & 583 & 93,6 \\
\hline
\end{tabular}

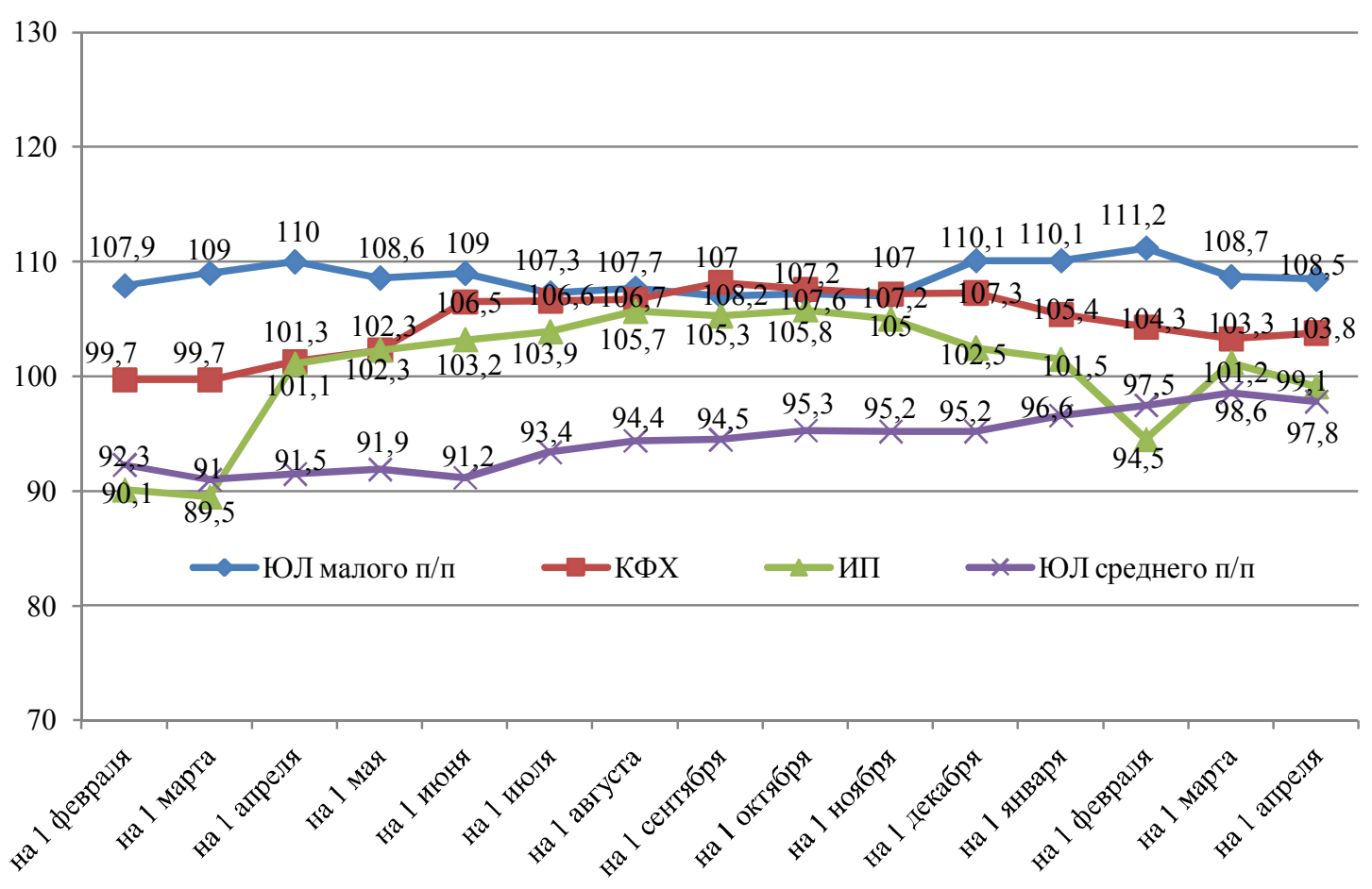

Рис. 2. Сравнительный анализ количества действующих субъектов МСП за 20172. и 1 квартал 2018 года

Источник - Комитет по статистике Министерства национальной экономики Республики Казахстан-2018г. 
Одним из направлений развития предпринимательской деятельности является развитие государственно-частного партнерства, которое позволит привлечь частные средства для реализации инновационных проектов, создать условия для реализации бизнес-проектов, имеющих как общегосударственное, так региональное значение. Основной приоритет развития государственно-частного партнерства состоит в том, что государственные органы определяют основные формы и направления взаимодействия с частным бизнесом.

Государство оказывает существенное прямое или косвенное воздействие на развитие частного сектора экономики, оно выступает и как экономический партнер и как регулятор. Гарантии государства по поддержке государственно-частного партнерства являются необходимыми основами его осуществления.

Роль государственно-частного партнерства состоит в снижении предпринимательских и инвестиционных рисков в сферах исследований и разработок, распространении новых технологий, развитии транспортной, энергетической и коммунальной инфраструктуры.

В рамках государственно - частного партнерства необходима дальнейшая консолидация бизнеса. Для решения этой задачи в Казахстане функционирует Национальная палата предпринимателей РК, которая стала надежным и компетентным партнером Правительства (4).

Количество граждан, решивших вести собственный бизнес, напрямую зависит от тех условий, которые создает государство для развития мелкого и среднего предпринимательства. По результатам опроса для успешного развития малого и среднего бизнеса необходимо:

- изменить правила регистрации, лицензирования, сертификации и т. д. (75,0% респондентов);

- улучшить систему налогообложения предпринимателей $(62,5$ \%);

- совершенствовать финансово-кредитную регуляцию $(56,3 \%)$;

- упростить отчетности и бухучета $(25,0 \%)$

- обеспечить безопасность бизнеса $(25,0 \%)$

- улучшить информационное обеспечение граждан, работающих в этой сфере (25\%);

- совершенствовать лизинговое обслуживание $(6,3 \%)$.

По мнению экспертов, ожидать крупных успехов в развитии казахстанского малого и среднего предпринимательства в ближайшие годы возможно. Одной из главных причин медленного продвижения реформ в сфере малого и среднего бизнеса в предыдущие годы явилось неверие людей в малый бизнес как в постоянную работу, обеспечивающую стабильный и долгосрочный доход. Теперь же стабильности больше, убеждения у людей меняются, поэтому именно сейчас государственная поддержка может дать значительные результаты», отметили опрошенные специалисты.

Дальнейшее развитие малого предпринимательства с целью создания новых рабочих мест, насыщения товарного рынка отечественными товарами и услугами, повышения инновационной активности хозяйствующих субъектов, как показывает опыт развитых стран, невозможно без специальных мер государственной поддержки.

Реализация первоочередных мер Программ направлена, прежде всего, на разрешение проблем, сдерживающих развитие малого бизнеса:

- недостаточная развитость инфраструктуры поддержки малого бизнеса предпринимательства;

- слабая дисциплина по исполнению действующего законодательства на местном уровне;

- чрезвычайная усложненность систем налогообложения и налоговых проверок;

- ограниченность доступа к кредитам на приобретение основных и пополнение оборотных средств;

- сложность процедуры приобретения незадействованных производственных помещений, находящихся в коммунальной собственности, субъектами малого предпринимательства, занятыми в реальном секторе экономики и крайне высокая арендная плата;

- отсутствие целостной системы подготовки кадров и информационной поддержки малого предпринимательства;

- организационные проблемы взаимодействия малого предпринимательства с государственными структурами;

- административные барьеры на пути развития малого предпринимательства (5).

Таким образом, можно сделать вывод, что фундамент развитой системы государственной поддержки бизнеса должны составлять:

- оптимальная законодательная и нормативная база, определяющая цели государственной политики и регулирующих весь комплекс вопросов поддержки предпринимательской деятельности; 
- разработка и реализация системы государственных программ финансового, технологического, информационного, консультационного, кадрового содействия;

- сочетание прямых и косвенных мер поддержки малого предпринимательства;

- система специализированных институтов по поддержке малого бизнеса, как на уровне государства, так и на уровне крупных общенациональных общественных организаций;

- рост реальных доходов населения, так как только спрос со стороны населения, рождает предложение на товары и услуги МСП;

- гибкость системы приоритетов и разнообразие форм государственной поддержки при наличии согласованности и непротиворечивости мер;

- взаимодействие органов государственной власти различных уровней с союзами и объединениями, выражающими интересы предпринимателей;

- существенное улучшение системы учета и государственной статистики субъектов малого предпринимательства;

- проведение образовательной и пропагандистской компании.

\section{ЛИТЕРАТУРА}

1. Статистические данные Комитета по статистике Министерства национальной экономики Республики Казахстан. Астана 2017, 2018гг.

2. Указ Президента Республики Казахстан от 27 февраля 2014 года № 757 «О кардинальных мерах по улучшению условий для предпринимательской деятельности в Республике Казахстан». Астана. 2014.

3. Послание Президента Республики Казахстан Н. Назарбаева от 31 января 2017 г. народу Казахстана. «Третья модернизация Казахстана: глобальная конкурентоспособность». Астана. 2017.

4. Закон Республики Казахстан о частном предпринимательстве (с изменениями и дополнениями по состоянию на 03.12.2015 г.) Астана.2017

5. Предпринимательский кодекс Республики Казахстан (с изменениями и дополнениями по состоянию на 09.01.2018 г.). Астана.2018. 